\title{
Bilateral diffuse xanthogranulomatous pyelonephritis in end-stage renal disease (ESRD)
}

\author{
Pielonefrite xantogranulomatosa difusa bilateral na doença renal \\ em estágio final
}

\section{Authors}

Milena Regina dos Santos Perez ${ }^{1}$ Mirele Cristine Santos de Oliveira ${ }^{2}$ [D Danielle Bispo Vieira Ortiz ${ }^{1}$ Juliana Abeche Fermozelli ${ }^{3}$ William Luis Oliveira ${ }^{4}$ Ronaldo D'Avila' ${ }^{\text {(D) }}$

'Pontifícia Universidade Católica de São Paulo, Faculdade de Ciências Médicas e da Saúde, Sorocaba, SP, Brasil.

${ }^{2}$ Universidade de Marília, Marília, SP, Brasil.

${ }^{3}$ Pontifícia Universidade Católica de São Paulo, Faculdade de Ciências Médicas e da Saúde, Departamento de Cirurgia, Sorocaba, $\mathrm{SP}$, Brasil.

${ }^{4}$ Conjunto Hospitalar de Sorocaba, Sorocaba,SP, Brasil.

Submitted on: $11 / 12 / 2020$

Approved on: 04/18/2021.

\section{Correspondence to:}

Milena Regina dos Santos Perez. E-mail:milenah72@ hotmail.com

DOI: https://doi.org/10.1590/21758239-JBN-2020-0242
Xanthogranulomatous pyelonephritis (XGP) is a very rare form of kidney disease characterized by destruction of renal parenchyma, its fibrosis, and its replacement by lipid-laden macrophages. ${ }^{1,2}$.

We describe a case of a 46-year-old woman with bilateral staghorn stones and end-stage renal disease (ESRD) under renal replacement therapy by hemodialysis. An abdominal CT scan suggested bilateral XGP (figure) and she was submitted to bilateral nephrectomy. Histopathological analysis confirmed the diagnosis.

Complications in XGP can occur, such as cortical atrophy, abscesses, and kidney loss. The treatment of choice is total nephrectomy, and tumors and granulomatous diseases should be included in the differential diagnosis ${ }^{3-5}$.

\section{Authors' Contribution}

Milena Regina dos Santos Perez, Mirele Cristine Santos de Oliveira, Danielle Bispo Vieira Ortiz, Juliana Abeche Fermozelli, William Luis Oliveira and Ronaldo D'Avila contributed substantially to the conception or dewsign of the study; collection, analysis, or interpretation of data; writing or critical review of the manuscript; and final approval of the version to be published.
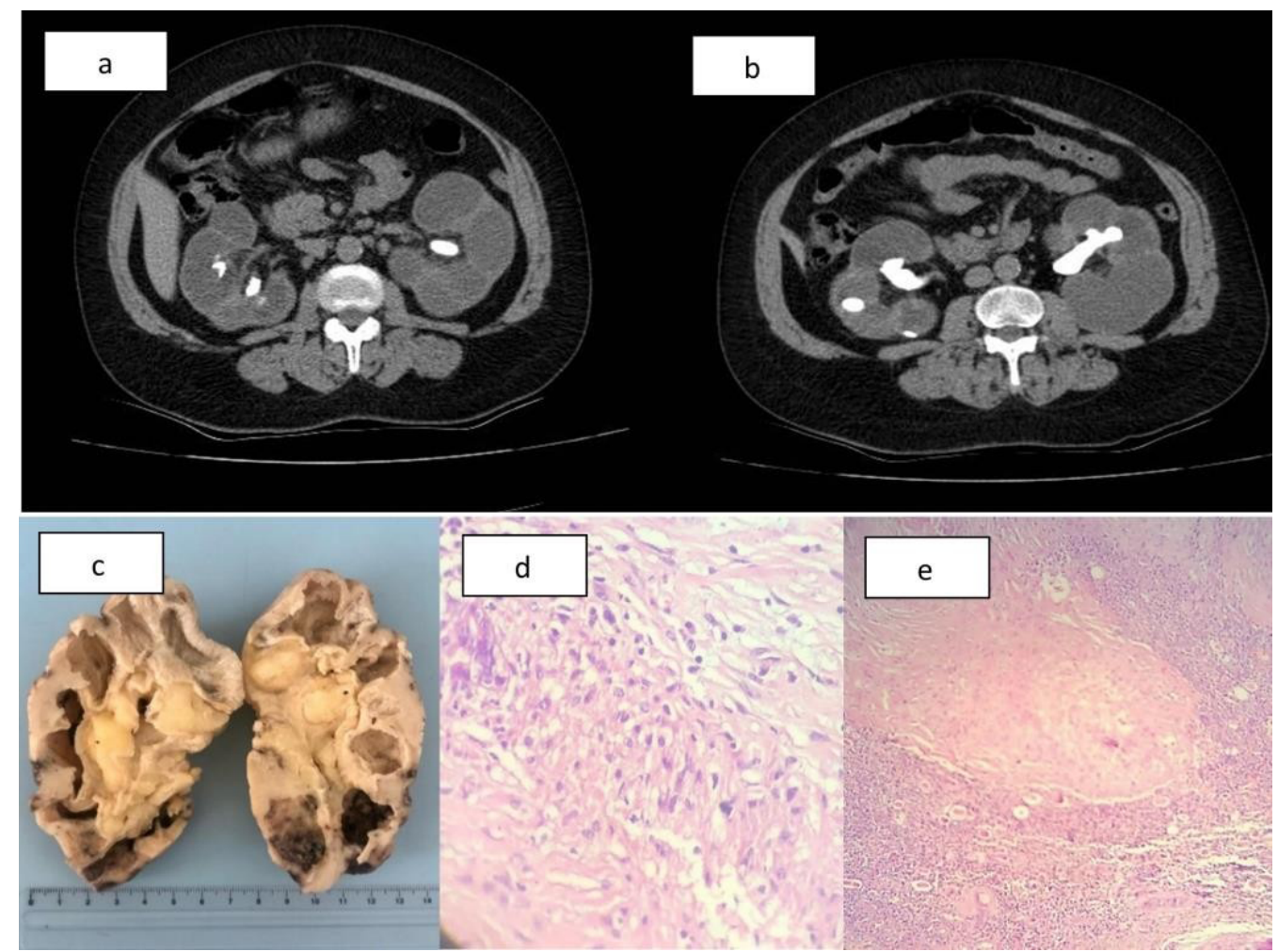

Figure 1. CT scan showing the "bear paw sign" in both kidneys (a) and staghorn stones with bilateral hydronephrosis (b). Gross pathological examination showing bilateral cystic formations, abscesses, and fibrosis with architectural distortion of the renal parenchyma (c). Optical microscopy showing numerous macrophages, some with xanthomized aspect (d) and renal parenchyma with focus of histiocytic reaction and areas of necrosis (e). 


\section{CONFLICT OF InTEREST}

The authors declare that they have no conflict of interest related to the publication of this manuscript.

\section{References}

1. Chuang CK, Lai MK, Chang PL, et al. Xanthogranulomatous pyelonephritis: experience in 36 cases.J Urol. 1992;147:333-336.
2. Parsons MA, Harris SC, Longstaff AJ, Grainger RG. Xanthogranulomatous pyelonephritis: a pathological, clinical, and etiological analysis of 87cases. Diagn Histopathol.1983; 6:203-219.

3. Kuo C, Wu C, Huang C, et al. Xanthogranulomatous pyelonephritis: critical analysis of 30 patients. Int Urol Nephrol. 2011; 43:15-22. doi:10.1007/s11255- 010-9778-8.

4. Ramboer K, Oyen R, Verellen S, et al.Focal Xanthogranulomatous pyelonephritis mimicking a renal tumor: CT- and MR findings and evolution under therapy. Nephrol Dial Transp. 1997; 12: 1028-1030.

5. Guzzo TJ, Bivalacqua TJ, Pierorazio PM, et al. Xanthogranulomatous pyelonephritis: presentation and treatment in the laparoscopy era. BJU Int. 2009; 104: 1265. 